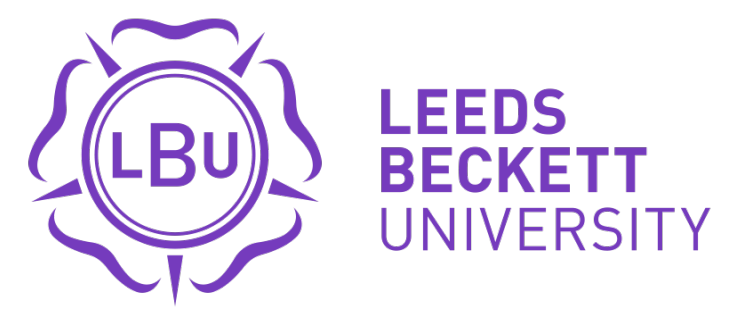

Citation:

McDougall, S and Vogt, KS and Wilkinson, A and Skull, J and Jones, GL (2019) Outcomes of delivering a fertility preservation service for women with cancer over a 12-year period at a UK assisted conception unit. Journal of Obstetrics and Gynaecology. ISSN 1364-6893 DOI: https://doi.org/10.1080/01443615.2019.1621823

Link to Leeds Beckett Repository record:

https://eprints.leedsbeckett.ac.uk/id/eprint/6151/

Document Version:

Article (Accepted Version)

Creative Commons: Attribution-Noncommercial-No Derivative Works 4.0

This is an Accepted Manuscript of an article published by Taylor \& Francis in Journal of Obstetrics and Gynaecology on 8 Aug 2019, available online: http://www.tandfonline.com/10.1080/01443615.2019.1621823

The aim of the Leeds Beckett Repository is to provide open access to our research, as required by funder policies and permitted by publishers and copyright law.

The Leeds Beckett repository holds a wide range of publications, each of which has been checked for copyright and the relevant embargo period has been applied by the Research Services team.

We operate on a standard take-down policy. If you are the author or publisher of an output and you would like it removed from the repository, please contact us and we will investigate on a case-by-case basis.

Each thesis in the repository has been cleared where necessary by the author for third party copyright. If you would like a thesis to be removed from the repository or believe there is an issue with copyright, please contact us on openaccess@leedsbeckett.ac.uk and we will investigate on a case-by-case basis. 


\section{Outcomes of delivering a Fertility Preservation Service for women with cancer over a 12-year period at a UK Assisted Conception Unit}

By

Sophia McDougall, Intercalated Medical Student, Medical School, The University of Sheffield, Sheffield, UK

Katharina S Vogt, Department of Psychology, Leeds Beckett University, Leeds, UK;

Anna Wilkinson, Intercalated Medical Student, Medical School, The University of

Sheffield, Sheffield,

Jonathan Skull, Jessop Wing, Sheffield Teaching Hospitals NHS Foundation Trust, Sheffield, UK

Georgina L Jones*, Department of Psychology, Leeds Beckett University, Leeds, UK;

To whom correspondence should be addressed: Professor Georgina Jones, Department of Psychology, School of Social Sciences, Leeds Beckett University, Calverley Building, City Campus, Leeds. Tel: 0113 8125106.Email: g.1.jones@1eedsbeckett.ac.uk

\section{Conflict of interest \& funding details}

The authors have no conflicts of interest to declare. This work did not receive any funding. 


\begin{abstract}
This service evaluation aimed to appraise the delivery of a fertility preservation service for women with cancer as part of an Assisted Conception Unit (ACU) in 2005. Firstly, the ACUdatabase was interrogated between $08 / 2005$ and $01 / 2017$; revealing 174 women received referrals over the 12-year period with a steady referral increase each year. Demographic analyses revealed factors, such as being partnered, to be strong indicators of whether women would seek FP or not. To improve service provision, women who had consented to be contacted for research, received questionnaires to ascertain their perspectives on the FP-decision-making process, outcomes and ACU after-care. The majority perceived their experience as excellent due to the care they received from ACU staff, speed and efficiency in service delivery. The increasing number of referrals since 2005 is reassuring. This audit also highlighted shortcomings of the service, such as limited awareness of the fertility counselling service and lack of after-care.
\end{abstract}

\title{
Keywords
}

fertility preservation, cancer, women, service delivery, assisted conception

\section{Impact statement}

What is already known on this subject?

There has been an increase in women diagnosed with cancer undergoing fertility preservation (FP) before starting potential gonadotoxic treatment. Offering FP to these women is essential as the ability to have future children is often perceived as equally as important as survivorship, and a source of hope for the future.

What do the results of this study add?

This study presents a service evaluation, across a 12-year period, of delivering FP services to women with cancer in one UK Assisted Conception Unit (ACU). Women's experiences of the service were evaluated to enhance service delivery and make recommendations for clinical practice.

What are the implications of these findings for clinical practice and/or future research?

The current service evaluation demonstrated increased rates of FP referral over a 12-year 
period for women with cancer. While this increasing number is reassuring and reflecting increased awareness among professionals and patients; shortcomings in the care pathway were also found: women reported limited opportunity to see fertility counsellors and desired better after care. This information may also be of benefit to other ACUs seeking to enhance and improve service provision in the care of women with cancer, contemplating fertility preservation. 


\section{Introduction}

Approximately 11,000 women of reproductive age are diagnosed with cancer in the UK each year (The Royal College of Physicians Royal College of Radiologists and Royal College of Obstetricians and Gynaecologists, 2007). Many of these women will be exposed to gonadotoxic cancer treatment and be at increased risk of premature ovarian failure and infertility. Fertility preservation (FP) methods are available to those patients wishing to preserve their future fertility potential.

The Human Fertilisation \& Embryology Authority (HEFA) is an independent regulator of fertility treatment within the UK (HEFA, 2018a). Through regular inspections of research centers and fertility clinics it ensures government safety standards and ethical rules are met (HEFA, 2018d). The HFEA has been collecting data from all UK-licensed fertility clinics on their performed treatment cycles and their outcomes since 1991 which is held on the HFEA register database (HEFA, 2018c). In their latest report in 2014, the HFEA listed 82 licensed fertility clinics offering IVF, with 52,288 women using the service and undergoing a total of 67,708 cycles (HEFA, 2016). This is a $4.8 \%$ increase on the number of IVF cycles from 2013, with the majority of women receiving IVF aged below 37 (the average age being 35 years).

This increase is a consequence of both increased demand from women seeking freezing for social reasons, such as career or relationship status (Von Wolff, 2015) but also medical reasons; in particular women diagnosed with cancer (Peate et al., 2009). As well as offering female cancer patients the opportunity to have potential biological offspring in the future; crucially, undergoing FP offers female cancer patients hope for a future after their cancer treatment (Tschudin and Bitzer, 2009; Vogt et al., 2018).

NICE guidelines state that all newly diagnosed patients with cancer must be made aware of the potential gonadotoxic effects of their treatment before commencement, and be offered alternative treatment options that could cause a lower degree of gonadal damage (National Institute for Health and Clinical Excellence, 2013). Factors, such as cancer type, proposed treatment regimen, patient age and relationship status, need to be considered when discussing and undergoing fertility preservation (Kim et al., 2016). Currently, several wellestablished FP strategies exist for women concerned over their future reproductive capacity due to potentially gonadotoxic medical treatments. These include mature oocyte and embryo cryopreservation, ovarian tissue cryopreservation and ovarian transposition and shielding (De Vos, Smitz and Woodruff, 2014). Despite the accomplishment of live births through ovarian tissue cryopreservation, this is still considered to be an experimental method, and thus 
somewhat controversial, with techniques for transplantation still evolving (Donnez and Dolmans, 2013; Oktay et al., 2016, 2018). Another potential fertility preserving method involves the use of gonadotrophin-releasing hormone $(\mathrm{GnRH})$ analogues to suppress ovarian function during treatment. The evidence however, regarding the effectiveness of this technique is currently insufficient (Donnez and Dolmans, 2013).

We aimed to evaluate in depth the clinical data gathered over the last 12 years of delivering such a fertility preservation service for women with cancer in one tertiary referral center. Women's perceptions of using this service was also explored. It was hoped this information would enable us to i) understand in more detail the demographics of the women who access this service, ii) identify the support needs of women accessing the service, and identify ways that the fertility preservation service could be improved.

\section{Methods}

\section{$\underline{\text { Materials }}$}

Medical records. ACU patient records were screened by SM to identify all women with a diagnosis of cancer who were offered a referral and allocated an appointment to discuss FP at the unit during the period August 2005 to January 2017. Patients were included regardless of whether they attended the unit or not and if FP treatment was subsequently undertaken. Medical records were retrieved from either the ACU's database or as paper notes.

Questionnaire. A study-specific questionnaire was developed. This was based upon a review of the existing literature, and the involvement of two medical students who were undertaking their Intercalated BMedSci at the Unit (SMD, AW), the clinical lead for the ACU (JS), who has many years of experience working within the service and a health psychologist (GJ). The questionnaire covered eight key topics (referral process, consent process, menstruation and fertility, the counselling service, use of eggs/embryos, cancer treatment, current situation, contact with the clinic, overall experience). Eight open-ended questions were added to provide participants with the opportunity to express their answers in greater detail (Supplementary file 1).

\section{$\underline{\text { Procedure }}$}


University of Sheffield ethics approval and Trust audit department approval for the evaluation of the service was also obtained. Medical records were entered into an SPSS (Version 21) database. No identifying information was recorded and all patients received a study-specific ID-number.

Women, who had signed a HFEA 'Disclosing Identifying Information' form consenting to be contacted for research, were sent study packs in the post (February/March 2017). Study packs contained a cover letter, information sheet, study-questionnaire (with corresponding ID number) and a pre-paid return envelope.

All statistical analysis was performed using SPSS version 22. Simple demographic data and participant responses were analysed using descriptive statistics, including Frequency and Valid Percentages (\%). The continuous variables, age and number of oocytes collected, fertilised and stored were analysed using summary statistics, comprising mean, standard deviation and range. A Pearson Chi Square test was performed on the data to test if a significant difference existed in the proportion of women who had a partner or were single at the time of their diagnosis and pursued FP.

\section{Results}

\section{Database interrogation}

\section{Participants}

One hundred and seventy-four women with cancer were offered and allocated an ACU referral over the 12-year period between 08/2005 and 01/2017. Figure 2 demonstrates the increase in referral rates; with the greatest number of referrals for the most recent year with complete data collection (2016). Seventeen different cancer diagnoses were identified; most commonly breast cancer (56.4\%), followed by Hodgkin's lymphoma (15.1\%) and cervical cancer $(6.4 \%)$. An overview of all cancer diagnoses is presented in Table 1. Mean age at the time of referral was 30.2 (SD 6.6; range 16-44).

At time of referral, $114(65.5 \%)$ women were married or partnered, $47(27.0 \%)$ were single. Information regarding the relationship status of 13 women in this study was unavailable at the time of data collection; however, none of these subsequently pursued FP. The 
relationship status of the rest was unknown. It was hypothesised that relationship status may have impacted upon the women's decision making. A Pearson Chi Square test was performed $\mathrm{X}^{2}[(1,148)=4.3], p=0.039$; supporting this.

Of the 174 referrals, three did not attend their appointment, 104 (59.8\%) pursued FP treatment following ACU consultation, 67 did not pursue FP after attending their appointment. Seventeen were not offered treatment (gynaecological cancers, advanced disease, poor prognosis) while 50 decided against preservation (low chances of success, previous children, cost/funding concerns). These reasons were documented in patient files, i.e. had been documented by the health care professionals following the appointment. Notes for two women revealed more detail: one woman perceived the process as too overwhelming; another felt freezing embryos would go against her religious beliefs. However, the overriding concern for the majority of women was the risk associated with delaying cancer treatment.

Of the 104 women, 58 (55.8\%) froze embryos, 38 (36.5\%) froze eggs and eight (7.7\%) froze both. With the exception of one woman who used donor sperm, all the remaining women used sperm from their partner for embryos. One hundred (96.2\%) women successfully managed to store at least one egg or embryo in their first cycle; four were unsuccessful (aged $33,34,35,42$ years).

The mean number of eggs collected in the 107 cycles performed was 10.2 (SD: 6.6, range: 0-39). Women who just froze oocytes, successfully froze a mean of 8.8 eggs (SD: 4.4, 2-19). Those who froze embryos only, stored a mean of five (SD: 4.3; 0-26). Of the eggs collected, $62.6 \%$ were successfully fertilised and $93.1 \%$ of these were subsequently successfully frozen as embryos. Seven $(4.5 \%)$ of the women who successfully stored eggs decided to destroy them post-treatment, most commonly due to a subsequent relationship breakdown.

Of those having successfully frozen eggs/embryos, $18(17.8 \%)$ were seen posttreatment. Seven $(5.9 \%)$ women have attempted to conceive using stored material; all had frozen embryos and were with partners. One used a surrogate. Overall, three live births were achieved. One woman was successful on her first cycle, another on her first cycle with a surrogate and the third woman had four cycles, with the first being unsuccessful, the next two resulting in a biological pregnancy (these were however terminated due to the foetus being diagnosed with cystic fibrosis) and the fourth cycle resulting in a pregnancy and live birth.

The four other women who underwent treatment cycles themselves or via surrogates, used all of their embryos but were unable to achieve a live-birth. 


\section{Questionnaire data}

\section{Participants}

Out of the 174 women who received referrals to the ACU, $92(52 \%)$ agreed to be contacted for service evaluation and research purposes. Ten patients were found to have deceased, resulting in 82 eligible patients. ACU staff recommended not to contact three patients due to personal circumstances. The remaining 79 were contacted, and 34 responded $(43 \%$ response rate). Participants' ages ranged from 19 to 47 years old (Mean: 33.5yrs; SD: 6.6). Twenty-four (70.6\%) had a partner at time of referral and ten $(29.4 \%)$ were single.

\section{Referral to $A C U$}

All were referred to the ACU due to a diagnosis of cancer between 2007-2017 ( $\mathrm{n}=34$, $100 \%)$. Twenty-three $(67.6 \%)$ women were offered a referral by their health care professional (HCPs) but nine requested it themselves. Five (14.7\%) were seen within three days of referral, $11(32.4 \%)$ within a week, 13 (38.2\%) within a month; only one woman waited longer than a month. Twenty-six (81.3\%) women perceived this as quicker than expected or as expected. However, only 11 women (33\%) felt they knew what would happen at their first consultation with the fertility expert.

\section{Decisions}

Twenty-eight (82.4\%) women chose FP. Eighteen women $(64.3 \%)$ indicated that they froze embryos, 8 (28.6\%) eggs and two (7.1\%) froze both. However, when merging the data on the existing SPSS file, it became apparent that one participant froze eggs rather than embryos.

\section{Fertility counselling service}

Only 12 (35.3\%) women were aware of the fertility psychosocial counselling service, with $21(61.8 \%)$ not being aware and one (2.9\%) woman not sure. Twelve (35.3\%) women 
were offered the opportunity to speak to a counsellor, compared to nine $(26.5 \%)$ who weren't and $13(38.2 \%)$ who weren't sure. Only five (16.1\%) women saw a fertility counsellor. Those who have used the service, were either 'Very Satisfied' $(n=2)$ or were 'Satisfied' $(n=3)$.

\section{Informed decisions \& consent}

Most were happy with the amount of time available to consider FP although one (3.8\%) woman wished she had been given more time. Around 3/4 (70.4\%) felt they fully understood the information, with twenty-five $(92.6 \%)$ women feeling that they were given enough information to make an informed decision. All of the women felt that the consent process was explained by the appropriate person and $25(92.6 \%)$ women felt that they fully understood what they were consenting to at the time.

\section{Post cancer-treatment}

\section{Periods}

Initially, periods had stopped in $27(84.4 \%)$ of the 34 women. They have since returned in $63.2 \%$ of patients. However, $41.7 \%$ still do not have regular cycles.

\section{Follow-up appointments}

Only nine (29\%) women stated that they were offered follow-up appointments; 20 (64.5\%) were not, two (6.5\%) did not know. At the time of completion, 25 (73.5\%) had finished cancer treatment but only five had undergone blood tests to evaluate ovarian function.

When asked if women would routinely like follow-up appointments to discuss fertility, the majority (62.5\%) declared that they would. Among these, there were conflicting wishes as to how long after cancer treatment this should be which included 6 months post treatment completion, after 1 year, after two years, and when the woman feels ready.

\section{Outcomes \& use of stored material}

Three women have since used their eggs/embryos. One used a surrogate (live birth, first cycle), one had one cycle herself resulting in a live birth and the third woman had four cycles which ultimately resulted in one live birth (one cycle unsuccessful, two terminations due to 
foetus being diagnosed with cystic fibrosis). All had frozen embryos. Sixteen of the remaining women who stored material, have thought about using them, three have not and five feel that it is not suitable for them at present (missing $\mathrm{n}=1$ ).

When asked if the women knew what to do about using stored material, fifteen $(60 \%)$ said they would, seven (28\%) said they wouldn't know and three (12\%) weren't sure. Similarly, fourteen $(56 \%)$ said that they would know who to talk to in order to use their eggs/embryos, seven $(28 \%)$ said that they wouldn't and four (16\%) said that they didn't know. One woman wrote: "If I can't conceive naturally, I shall be using them but I don't know how I would do this/who to contact". (STH42).

The majority (63.6\%) of women have not been back in contact with the ACU since storing eggs/embryos. Twelve (36.4\%) had been in contact to discuss using their eggs/embryos, check their fertility or ensure reception of storage letters. When asked whether they knew how to contact the clinic if they needed, 25 (78.1\%) said they would, five (15.6\%) said they wouldn't and two (6.3\%) said they don't know (missing n=2).

Women who had finished their cancer treatment were asked whether they had thought about trying to become pregnant since $(n=25)$. Seven $(36.8 \%)$ said they did not want a family yet, two $(10.5 \%)$ had been advised not to have a pregnancy yet, three $(15.8 \%)$ were currently trying, two (10.5\%) had conceived naturally, two (10.5\%) had conceived through fertility treatment and three $(15.8 \%)$ did not know (missing $n=6)$. For more than half the women, having children was still important for the future, for nine (31.0\%) it was important at the moment, one (3.4\%) not at the moment, two (6.9\%) not at all and one $(3.4 \%)$ did not know (missing $\mathrm{n}=5)$.

Women were then given the option to express additional comments regarding their current situation and views on having children. A number of women noted the added complications that they now faced (e.g. not being able to bear a child anymore, trying to find a surrogate). A number of women also explained the impact of not being in a relationship and concerns for finding a donor. One woman wrote:

"I do want children but am not in a relationship. Also, I cannot bear a child anymore (the radiotherapy made me sterile) so I have the added complication of finding a surrogate." (STH01) 
Some women felt unsure whether becoming pregnant would be the right thing to do because of the chance of their cancer recurring.

"Knowing the first five years are the 'danger periods' for my cancer returning, I feel that I need to get through this period without a relapse before I have children as it would be unfair to bring a child into the world not being in a long remission period. Once through this period, I will consider using my eggs if I am in a relationship or feel able to go it alone”. (STH25)

A few women did want to start planning a family but were unsure how to go about this.

"I am unable to conceive due to my treatment, I have eggs and embryos stored/frozen but I am unsure of my options if I wanted to use them/surrogate. The cost/legislation is confusing”. (STH29)

\section{Overall experience}

When asked to rate the FP service overall (scale: 'Extremely poor'- 'Excellent'), 14 (43.8\%) rated the service as 'Excellent', followed by ten $(31.3 \%)$ 'Very good', four $(12.5 \%)$ 'Good', three (9.4\%) 'Neither good or bad' and one (3.1\%) 'Extremely poor' (missing n =2) Table 2 outlines comments from the women, as they were given opportunity to justify their rating.

\section{Discussion}

It is now recognized as essential that, upon cancer diagnosis, women at risk of losing their fertility as a consequence of cancer treatment have the opportunity to discuss their FP options (Hoeg, Schmidt and Macklon, 2016). These discussions should be clearly documented in the patient's medical records (Oktay et al., 2018). As a result, much recent literature focuses on women's experiences of receiving fertility-related information around the time of diagnosis and their decision making at time of cancer diagnosis (e.g. Peate et al., 2009; Hershberger et al., 2012; Vogt et al., 2018). While this increase in research is encouraging, limited literature exists investigating the demographics of women who have had referrals to the ACU for FP, subsequently had cancer treatment and now have stored cryopreserved material. 
Furthermore, it is essential to evaluate the women's experiences with the ACU service provision, their outcomes as well as experiences with the service in a retrospective manner in order to continually make improvements for patients.

This service audit found a steady increase in women being offered, and seeking, FP referral since 2005, as demonstrated in Figure 2. Reasons for this may include increased awareness, both for patients and clinicians, advances in FP, more efficient referral pathways, enhanced information access and updated NICE guidelines (NICE, 2013).

Being partnered was found to be a strong predictor for referral and the decision for undergoing FP; a finding which is supported in the literature (Gorman et al., 2012; Hershberger et al., 2012; Peddie et al., 2012; Mersereau et al., 2013; Corney and Swinglehurst, 2014; Corney, Puthussery and Swinglehurst, 2014). Single women commonly report feeling more vulnerable when pursuing FP without a partner to provide emotional and practical support; as well as anxieties about rejections from future partners (e.g. Corney and Swinglehurst, 2014). Relationship status however may also affect events post-treatment: for example, seven women decided to destroy their eggs or embryos since finishing treatment; the most common reason being break-down in the relationship with their FP partner. Thus, ensuring cancer patients are fully informed of the future ethical problems associated with freezing embryos, even if in a long-term committed relationship is therefore of utmost importance. Freezing both oocytes and embryos could mitigate these issues and allow greater flexibility for those who have a change in relationship-status after treatment. Other reasons reported against FP (age, funding, parity and not wanting to delay CT) are concurrent with those in the literature (e.g. Peate et al., 2009; G. Jones et al., 2017; Vogt et al., 2018). Women were generally satisfied with the ACU referral pathway. The majority were offered a referral without asking from their HCPs and felt that their referral was quicker than they expected; only one woman waited longer than a month. Over a quarter requested their own referrals, indicating knowledge of the potential impact of CT on fertility, as suggested above.

The majority of women however have little prior knowledge of these effects, stressing the need for HCPs to initiate discussions on the topic (Crawshaw et al., 2009; Corney and Swinglehurst, 2014; Hoeg, Schmidt and Macklon, 2016). Therefore, information provision at time of referral is of utmost importance to empower women to make informed choices over their fertility - even if they do not subsequently opt to have FP (Lee et al., 2011). 
Women wishing to have FP must make an appointment to go through necessary information to sign consent forms (HEFA, 2018b). The majority of women from this service were content with this process, indicating enough time and information was available for informed decision-making. However, evidently, not all women fully understood what they were consenting to; one woman even reported the wrong outcome in her questionnaire. Two further women in this study expressed having to rush their FP decision due to their diagnosis and treatment. To ensure that supported and informed decisions are made which are not rushed, the service must therefore offer comprehensive consent procedures for its patients - despite limited time available.

Results indicate that only seven women have attempted to conceive using their stored material; low return rates are also reported for other UK ACUs (Yap and Davies, 2007). A potential explanation is that not all women subsequently lose their fertility as a result of cancer treatment, but as ACUs are not routinely notified of natural births in women who previously underwent FP or whether their fertility was impaired post-treatment; this cannot be confirmed for this sample. On the other hand, low pregnancy rates in female cancer survivors are generally reported in the literature (Anderson et al., 2018); which may suggest that this low return rate maybe a consequence of the population itself. For example, women might be concerned about well-being or may be suffering emotional distress caused by the cancer diagnosis or treatment making them less likely to use stored material. Additionally, it is also likely that some women - especially those with the more recent diagnoses - are not yet ready to get pregnant due to the suggested five-year observational period and wait between completion of treatment and pregnancy. Therefore, long-term studies and evaluation of individual cases is needed to shed more light into the return rates of fertility preservation in female cancer patients who have stored material in the ACU.

After-care of FP patients has been judged as inadequate in a number of studies (Zebrack, Casillas and Nohr, 2004; Zebrack, 2008; Gorman et al., 2012). Patient's unmet needs were similarly identified in the current study, with approximately half of women unsure how to go about using their stored material and not knowing who to talk to. Women expressed the additional dilemma they now face in deciding whether to use their stored material. Concerns included the chances of their cancer recurring, eligibility for funding, the need for a surrogate and the absence of a partner. Feeling overwhelmed by the associated cost (treatment cost, services, pursuing adoption/surrogacy) is concurrent with past research (Gorman et al., 2010). 
Elsewhere, women have also described thoughts of guilt and selfishness for desiring children when they may have a shorter life-span (Gonçalves, Sehovic and Quinn, 2014).

Evidently, fertility epitomises a significant issue for most women in the study - both before and after cancer treatment- with $86 \%$ stating that having children at present or in the future is important. This is a common theme amongst cancer survivors (Tschudin and Bitzer, 2009; Lee et al., 2011; Hill et al., 2012; Nilsson et al., 2014), with issues related to infertility negatively impacting on cancer survivors' well-being and quality-of-life after cancer (Tschudin and Bitzer, 2009; Gonçalves, Sehovic and Quinn, 2014; Nilsson et al., 2014). A 2012 study (Gorman et al., 2012) reported that many women felt anxious and worried about whether they would be able to conceive in the future, but postponed seeking information about fertility due to fears of being told they were infertile. Unfortunately, cancer survivors often have a shorter fertility time-frame due to an earlier ovarian decline and therefore delaying fertility tests could hinder their chances of biological parenthood. In the present audit, less than $30 \%$ of women were offered a follow-up appointment, suggesting that many women could benefit from this service being offered and encouraged after cancer treatment. Worries about treatment-induced infertility have been shown to contribute to long-term symptoms of depression (Gorman et al., 2010), reiterating the need for the service to improve the support it provides to its patients after their FP treatment has finished.

Nonetheless, overall, around $50 \%$ of patients in this audit perceived their experience at the ACU as excellent due to the care they received from staff, speed and efficiency in the service delivery. Suggestions for improvement from the participants included quicker referrals, superior knowledge of funding guidelines and increased after-care.

\section{Limitations of the study}

A number of study limitations arise. Due to the study spanning a 12-year period, women included in the study may have seen different ACU HCPs, which may have impacted on their experience. The retrospective nature of the study meant that some women used the service more than 10 years ago and may now be in remission or have given birth to a child, thus altering perspectives of their experiences. Perceptions may have also changed over time or some aspects may have been forgotten. The questionnaire had a response rate of 44.3 per cent. 
Therefore, it is uncertain as to what extent the responses are representative of the experiences of women who have used the service in general. Women who had a particularly negative or positive experience may have chosen to respond to the questionnaire, resulting in a potentially biased sample. The study did however have a diverse participant sample in terms of age, cancer diagnosis, relationship status and FP decision. Measures were used in an effort to increase the response rate (reminder letter, pre-paid envelope). Due to the study being conducted at one UK ACU, data may not be representative of women who have used a FP service at other UK centers. The results obtained however were very similar to those of other studies conducted in the UK.

Another potential limitation of the current study is the fact that fertility preservation treatment has changed, and improved, drastically within the 12-year study period: it may explain the increase in number of referrals since 2005. Finally, data regarding patients' endocrine function at follow-up would have been an important addition to the study but was not available at the point of data collection.

\section{Clinical Implications}

The first important clinical implication arises from characteristics of ACU referrals. The majority of women as expected ( $>50 \%$ ) had breast cancer diagnoses, however there was a large range of other diagnoses. A retrospective study identified disparities in the referral practices of practitioners belonging to different oncology divisions, with women diagnosed with breast cancer or lymphoma more likely to receive a referral than women diagnosed with other malignancies (Bastings et al., 2014). These findings therefore stress the importance of attentiveness to FP across all cancer and non cancer specialties.

Prior to their first ACU appointment, only 1/3 felt they knew what would happen once they arrived- a finding which is echoed in a similar questionnaire-based study (Hill et al., 2012). HCPs who are involved in organising referrals, should therefore take time to prepare women for their ACU appointment by giving verbal or written information, or online-based resources, such as decision-aids (G. L. Jones et al., 2017).

Once the ACU referral has taken place, it is critical that patients are offered the opportunity to see a fertility psychosocial counsellor who specialises in support and therapeutic counselling, due to the sensitive nature of decisions they are required to make. However, only $35 \%$ of women at this ACU reported that they had been given the opportunity to speak to a fertility counsellor. Also, only $1 / 3^{\text {rd }}$ of women indicated they were aware of this service at the 
time of FP with only five using the service; this is coherent with previous research reporting only few onco-fertility patients are offered this (Crawshaw et al., 2009; Hill et al., 2012; Corney and Swinglehurst, 2014; Goetsch, Volk and Woodruff, 2014).

Despite FP offering much hope for future biological offspring and taking some concerns and emotional burdens off women with new diagnoses of cancer (Hoeg, Schmidt and Macklon, 2016), women also need to be informed that the chances for live births from FP are still relatively low. Fertility counselling therefore fulfills the purpose of providing the women with up-to date factual information, a crucial aspect of good clinical practice. As a result, the number of women offered FP need to be improved to ensure women are aware of all aspects of their decisions. This lack of supported decision making is concerning, and gives rise to (future) emotional conflict and miss-informed decisions; therefore, it is paramount that all women diagnosed with cancer receive ACU referral as well as fertility counselling service, in concordance with recommendations and guidelines from appropriate regulatory bodies.

\section{Conclusion}

In conclusion, our evaluation of the current service has demonstrated an increasing number of women referred to the ACU as a result of cancer diagnoses. The increasing number is reassuring, reflecting the recognized need for young female cancer patients to be given the chance to discuss FP and to give them the opportunity to have future biological offspring, if desired and providing diagnosis and prognosis allow. However, shortcomings in the care of these women were evident, especially around limited opportunity to see a fertility counsellor, lack of information provision to support women's FP knowledge base and decision-making as well as better after care. These factors should be addressed in order to improve service provision for these women in the future. 
Anderson, R. A. et al. (2018) 'The impact of cancer on subsequent chance of pregnancy : a population- based analysis', 33(7), pp. 1281-1290. doi: 10.1093/humrep/dey216.

Bastings, L. et al. (2014) 'Referral for fertility preservation counselling in female cancer patients.', Human reproduction (Oxford, England), 29(10), pp. 2228-37. doi:

10.1093/humrep/deu186.

Corney, R. H. and Swinglehurst, A. J. (2014) 'Young childless women with breast cancer in the UK: A qualitative study of their fertility-related experiences, options, and the information given by health professionals', Psycho-Oncology, 23(1), pp. 20-26. doi: 10.1002/pon.3365. Corney, R., Puthussery, S. and Swinglehurst, J. (2014) 'The stressors and vulnerabilities of young single childless women with breast cancer: A qualitative study', European Journal of Oncology Nursing, 18(1), pp. 17-22. doi: 10.1016/j.ejon.2013.10.003.

Crawshaw, M. A. et al. (2009) 'Male and female experiences of having fertility matters raised alongside a cancer diagnosis during the teenage and young adult years', European Journal of Cancer Care, 18(4), pp. 381-390. doi: 10.1111/j.1365-2354.2008.01003.x. Donnez, J. and Dolmans, M.-M. (2013) 'Fertility preservation in women', Nature Publishing Group, 9(10). doi: 10.1038/nrendo.2013.205.

Goetsch, A., Volk, A. and Woodruff, T. K. (2014) 'Genetic Counselors: Bridging the Oncofertility Information Gap', in Oncofertility Communication. New York, NY: Springer New York, pp. 87-98. doi: 10.1007/978-1-4614-8235-2_7.

Gonçalves, V., Sehovic, I. and Quinn, G. (2014) 'Childbearing attitudes and decisions of young breast cancer survivors: A systematic review', Human Reproduction Update, 20(2), pp. 279-292. doi: 10.1093/humupd/dmt039.

Gorman, J. R. et al. (2010) 'Depressive symptoms among young breast cancer survivors: The importance of reproductive concerns', Breast Cancer Research and Treatment, 123(2), pp. 477-485. doi: 10.1007/s10549-010-0768-4.

Gorman, J. R. et al. (2012) 'How do you feel about fertility and parenthood? The voices of young female cancer survivors', Journal of Cancer Survivorship, 6(2), pp. 200-209. doi: 10.1007/s11764-011-0211-9.

HEFA (2016) Fertility treatment 2014: Trends and figures. Available at: https://www.hfea.gov.uk/media/1783/fertility-treatment-2014-trends-and-figures.pdf. HEFA (2018a) About us. Available at: https://www.hfea.gov.uk/about-us/ (Accessed: 30 May 2018).

HEFA (2018b) Giving consent: A guide for patients and their partners. Available at: 
https://ifqlive.blob.core.windows.net/umbraco-website/1460/giving-consent-a-guide-forpatients-and-their-partners.pdf.

HEFA (2018c) How we manage your data.

HEFA (2018d) How we regulate. Available at: https://www.hfea.gov.uk/about-us/how-weregulate/ (Accessed: 30 May 2018).

Hershberger, P. E. et al. (2012) 'The decision-making process of young adult women with cancer who considered fertility cryopreservation.', Journal of obstetric, gynecologic, and neonatal nursing : JOGNN, 42(1), pp. 59-69. doi: 10.1111/j.1552-6909.2012.01426.x. Hill, K. A. et al. (2012) 'Experience of young women diagnosed with breast cancer who undergo fertility preservation consultation', Clinical Breast Cancer. Elsevier, 12(2), pp. 127132. doi: 10.1016/j.clbc.2012.01.002.

Hoeg, D., Schmidt, L. and Macklon, K. T. (2016) 'Young female cancer patients ' experiences with fertility counselling and fertility preservation - a qualitative small-scale study within the Danish health care setting', 9734(August 2017), pp. 283-288. doi: 10.1080/03009734.2016.1204394.

Jones, G. et al. (2017) 'What factors hinder the decision-making process for women with cancer and contemplating fertility preservation treatment?', Human Reproduction Update, 23(4), pp. 433-457. doi: 10.1093/humupd/dmx009.

Jones, G. L. et al. (2017) 'Observational study of the development and evaluation of a fertility preservation patient decision aid for teenage and adult women diagnosed with cancer: the Cancer, Fertility and Me research protocol', BMJ Open, 7(3), p. e013219. doi: 10.1136/bmjopen-2016-013219.

Kim, S. Y. et al. (2016) 'Toward precision medicine for preserving fertility in cancer patients: Existing and emerging fertility preservation options for women', Journal of Gynecologic Oncology. doi: 10.3802/jgo.2016.27.e22.

Lee, R. J. et al. (2011) 'Facilitating reproductive choices: The impact of health services on the experiences of young women with breast cancer', Psycho-Oncology, 20(10), pp. 10441052. doi: 10.1002/pon.1826.

Mersereau, J. E. et al. (2013) 'To preserve or not to preserve: how difficult is the decision about fertility preservation?', Cancer, 119(22), pp. 4044-50. doi: 10.1002/cncr.28317. National Institute for Health and Clinical Excellence (2013) 'Fertility problems: assessment and treatment.', National Institute for Health and Care Excellence, (February 2013), p. 51. Nilsson, J. et al. (2014) “"Will I be able to have a baby?” Results from online focus group 
discussions with childhood cancer survivors in Sweden', Human Reproduction, 29(12), pp. 2704-2711. doi: 10.1093/humrep/deu280.

Oktay, K. et al. (2016) 'First pregnancies, live birth, and in vitro fertilization outcomes after transplantation of frozen-banked ovarian tissue with a human extracellular matrix scaffold using robot-assisted minimally invasive surgery', American Journal of Obstetrics and Gynecology. doi: 10.1016/j.ajog.2015.10.001.

Oktay, K. et al. (2018) 'Fertility preservation in patients with cancer: ASCO clinical practice guideline update', Journal of Clinical Oncology. doi: 10.1200/JCO.2018.78.1914.

Peate, M. et al. (2009) 'The fertility-related concerns, needs and preferences of younger women with breast cancer: A systematic review', Breast Cancer Research and Treatment, 116(2), pp. 215-223. doi: 10.1007/s10549-009-0401-6.

Peddie, V. L. et al. (2012) 'Factors affecting decision making about fertility preservation after cancer diagnosis: A qualitative study', BJOG: An International Journal of Obstetrics and Gynaecology, 119(9), pp. 1049-1057. doi: 10.1111/j.1471-0528.2012.03368.x. The Royal College of Physicians Royal College of Radiologists and Royal College of Obstetricians and Gynaecologists (2007) Report of a Working Party of the Royal College of Physicians Royal College of Radiologists and Royal College of Obstetricians and Gynaecologists. The Effects of Cancer Treatment on Reproductive Functions: Guidance on Management. London, England.

Tschudin, S. and Bitzer, J. (2009) 'Psychological aspects of fertility preservation in men and women affected by cancer and other life-threatening diseases', Human Reproduction Update, 15(5), pp. 587-597. doi: 10.1093/humupd/dmp015.

Vogt, K. S. et al. (2018) 'Preserving fertility in women with cancer ( PreFer ): Decision making and patient - reported outcomes in women offered egg and embryo freezing prior to cancer treatment', Psycho-Oncology, 27(12), pp. 2725-2732. doi: 10.1002/pon.4866.

De Vos, M., Smitz, J. and Woodruff, T. K. (2014) 'Fertility preservation in women with cancer', The Lancet. Elsevier Ltd, 384(9950), pp. 1302-1310. doi: 10.1016/S01406736(14)60834-5.

Von Wolff, M. (2015) 'Fertility Preservation of Non-Medical Reasons', Deutsches Ärzteblatt International, 112, pp. 27-32. doi: 10.3238/arztebl.2015.0027.

Yap, J. K. W. and Davies, M. (2007) 'Fertility preservation in female cancer survivors', Journal of Obstetrics and Gynaecology, 27(4), pp. 390-400. doi:

$10.1080 / 01443610701327412$. 
Zebrack, B. (2008) 'Information and service needs for young adult cancer patients', Supportive Care in Cancer, 16(12), pp. 1353-1360. doi: 10.1007/s00520-008-0435-z.

Zebrack, B., Casillas, J. and Nohr, L. (2004) 'Fertility issues for young adult survivors of childhood cancer', Psycho-Oncology, 699(May 2003), pp. 689-699. doi: 10.1002/pon.784. 


\section{$\underline{\text { Supplementary files }}$}

Figure 1: Patient flow throughout the study

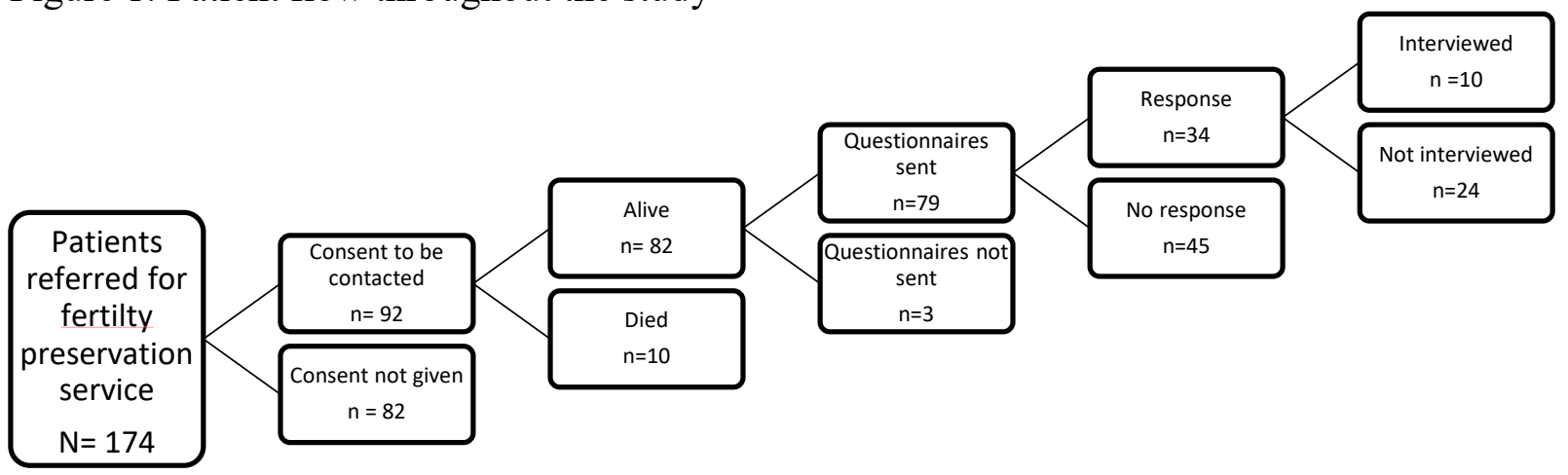

Figure 2: Number of ACU referrals of women diagnosed with cancer

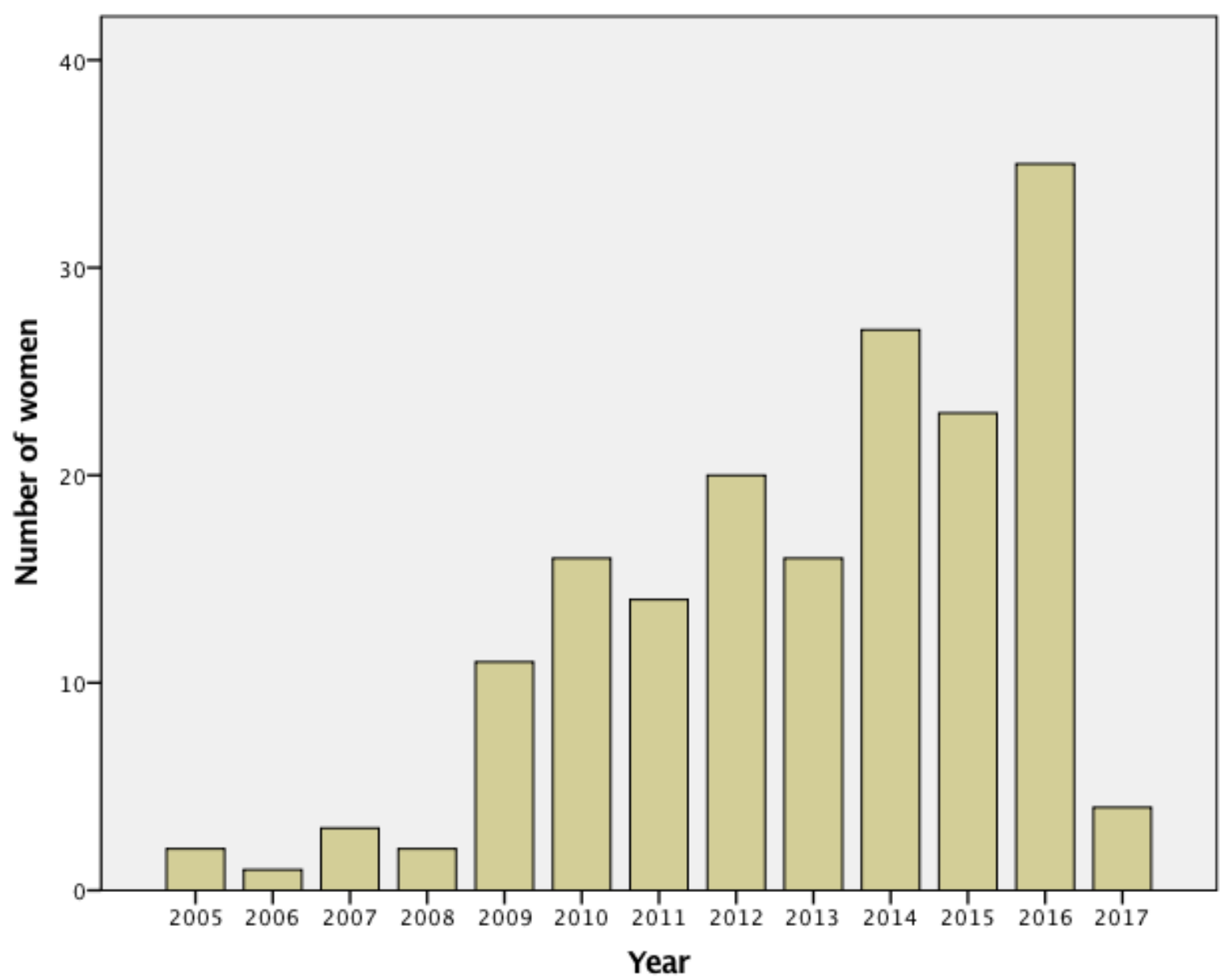


Table 1: Women referred to the ACU: cancer diagnoses

\begin{tabular}{|l|l|}
\hline Cancer Type & $N(\%)$ \\
\hline Breast & $97(56.4)$ \\
\hline Hodgkin's Lymphoma & $26(15.1)$ \\
\hline Cervical & $11(6.4)$ \\
\hline Brain & $8(4.7)$ \\
\hline Ovarian & $7(4.1)$ \\
\hline Bowel Cancer & $5(2.9)$ \\
\hline Endometrial & $4(2.3)$ \\
\hline Acute Myeloid Leukaemia & $3(1.7)$ \\
\hline Non-Hodgkin's Lymphoma & $2(1.2)$ \\
\hline Nasopharyngea & $2(1.2)$ \\
\hline Adrenal & $1(0.6)$ \\
\hline Melanoma & $1(0.6)$ \\
\hline Tonsil & $1(0.6)$ \\
\hline Chronic Myeloid Leukaemia & $1(0.6)$ \\
\hline Sarcoma & $10.6)$ \\
\hline
\end{tabular}


Table 2: Service ratings

\begin{tabular}{|c|c|c|}
\hline Feedback score given & Reasoning & $\begin{array}{l}\mathrm{N} \\
\text { (missing } \mathrm{n}=2 \text { ) }\end{array}$ \\
\hline Excellent & $\begin{array}{l}\text { "from the receptionist to the } \\
\text { embryologist, I was made } \\
\text { totally at ease" (STH52) } \\
\text { "all staff members were } \\
\text { considerate and friendly, } \\
\text { they appeared to go beyond } \\
\text { what you might expect", } \\
\text { (STH24). "very informative } \\
\text { but empathetic, kind and } \\
\text { supportive" (STH21) } \\
\text { "caring, friendly, } \\
\text { professional" (STH57) } \\
\text { "all the staff were incredibly } \\
\text { friendly and supportive to my } \\
\text { situation. Being so young } \\
\text { they tailored the care and } \\
\text { service they gave me, which } \\
\text { made me feel supported". } \\
\text { (STH10, aged 20) }\end{array}$ & 14 \\
\hline Very good & $\begin{array}{l}\text { "excellent care at the unit but } \\
\text { no after-care" (STH50) }\end{array}$ & 10 \\
\hline Good & $\begin{array}{l}\text { "given the incorrect } \\
\text { information regarding } \\
\text { funding for a second round of } \\
\text { treatment and this caused a } \\
\text { lot of distress at the time" } \\
\text { "all doctors should know } \\
\text { funding details necessary to } \\
\text { give correct advice" (STH20 }\end{array}$ & 4 \\
\hline
\end{tabular}




\begin{tabular}{|l|l|l|}
\hline Neither good nor bad & & 3 \\
\hline Poor? & & \\
\hline Extremely poor & "People we had contact with & 1 \\
& did not listen so we lost all \\
& confidence in their ability to \\
& perform their medical tasks" & \\
& (STH31). & \\
\hline
\end{tabular}

